\title{
A RATIO DECIDENDI E A SUA ADEQUAÇÃO AO CASO CONCRETO
}

Jônatas Luiz Moreira de Paula ${ }^{1}$

Maristela Silva Fagundes Ribas ${ }^{2}$

PAULA, J. L. M. de; RIBAS, M. S. F. A Ratio Decidendi e a sua adequação ao caso concreto. Rev. Ciênc. Juríd. Soc. UNIPAR. Umuarama. v. 19, n. 1, p. 7585, jan./jun. 2016.

RESUMO: O Código de Processo Civil de 2015 adotou o uso dos precedentes judiciais, almejando que as decisões proferidas pelos tribunais superiores sirvam de referência vinculante no ordenamento jurídico. No entanto, seguindo o sistema de precedentes, um precedente judicial não poderá ser aplicado de maneira infundada, há a imposição de se comparar o caso concreto com a decisão paradigma. Para tanto, cumpre analisar o elemento que compõe o precedente e que opera a eficácia vinculante às decisões judiciais, a razão que enseja à decisão (ratio decidendi). Primeiramente, a análise será em face da sua definição e, num segundo momento, como ocorre a aplicação ao caso concreto, especialmente, quando necessário o uso da técnica da distinção (distinguishing), a fim de recusar o uso do precedente.

PALAVRAS-CHAVE: Distinção; Novo Código de Processo Civil; Precedentes vinculantes; Ratio decidendi.

\section{INTRODUÇÃO}

Há alguns anos o Brasil vem debatendo inovações no Direito Processual e, por consequência, medidas legislativas foram desencadeadas proporcionando a aplicação de casos já julgados para os que suscitassem a mesma análise, caracterizando-se, assim, a força do precedente sob os traços do common law, porém, desconsiderando as circunstâncias fáticas que incorreram no julgamento. Neste sentido, destacam-se a promulgação da Emenda Constitucional $\mathrm{n}^{\circ} 45$, de 2004, que introduziu no ordenamento as súmulas vinculantes emanadas pelo Supremo Tribunal Federal, bem como, a Lei $n^{\circ} 11.276$, de 2006, que acrescentou o $\S 1^{\circ}$ ao art. 518 (CPC de 1973) impedindo o seguimento do recurso de apelação quando a sentença estivesse de acordo com súmula do Supremo Tribunal Federal

${ }^{1}$ Pós-doutor em Direito pela Universidade de Coimbra. Doutor pela UFPR - Universidade Federal do Paraná. Mestre pela Universidade Estadual de Londrina. Professor titular da UNIPAR - Universidade Paranaense. Advogado. E-mail: jlmp@onda.com.br

${ }^{2}$ Aluna do Curso de Mestrado em Direito Processual e Cidadania pela UNIPAR- Universidade Paranaense. Professora das Faculdades Integradas Santa Cruz de Curitiba. Advogada. E-mail: marisfr@ hotmail.com

Rev. Ciênc. Juríd. Soc. UNIPAR, v. 19, n. 1, p. 75-85, jan./jun. 2016 
ou do Superior Tribunal de Justiça, dentre outras. Nota-se, portanto, a gradativa adesão ao sistema de precedentes, com efeito vinculante.

Diante disso, no âmbito do direito processual civil brasileiro, ainda se busca a vinculação do precedente a um caso similar como forma de estabilização das decisões judiciais, pois, resta incompreensível haver posicionamentos diversos, advindos dos tribunais, acerca de uma mesma conduta, submetendo as partes de um processo a julgamentos diferenciados. O que se busca é a razão de ser dos tribunais, ou seja, decisões proferidas que sirvam de modelo no ordenamento jurídico. $^{3}$

Neste sentido, Daniel Mitidiero (2016) afirma a necessidade da reconstrução do sistema judiciário, delimitando a função das Cortes de Justiça (tribunais regionais) e das Cortes de Precedentes (tribunais superiores), para o controle das decisões de primeira instância e para atribuir unidade ao direito mediante a formação de precedentes, respectivamente. Dessa forma, juízes de primeiro grau e os tribunais regionais devem observar os precedentes emanados dos tribunais superiores.

Nesse aspecto, ante a necessidade de um código eficiente a fim de proporcionar efetividade e segurança jurídica aos jurisdicionados, o Código de Processo Civil de 2015 busca a estabilidade da decisão ao dispor de um rol de precedentes com força obrigatória. Como finalidade, almeja aprimorar o processo civil brasileiro, impedindo decisões diferentes sobre a mesma norma jurídica e, concomitantemente, obedecendo às garantias constitucionais (CAMBI, 2016).

Nas palavras de Luiz Guilherme Marinoni, “embora a eficácia vinculante se destine a conferir segurança jurídica aos jurisdicionados, ela não se preocupa em garantir a indiscutibilidade ou a imutabilidade da precisa solução dada ao objeto litigioso, mas em tutelar a estabilidade da ordem jurídica, a previsibilidade e a igualdade." (MARINONI, 2013, p. 316),

Corroboram Cambi e Hellman (2016, p. 955) quando afirmam que "o Estado Democrático de Direito deve estar calcado na estabilidade e na continuidade da ordem jurídica. A previsibilidade das consequências jurídicas de determinada conduta são manifestações primárias da segurança jurídica."

Nota-se, que o Código de Processo Civil de 2015 optou por conduzir o direito brasileiro através do sistema de precedentes, com eficácia vinculante, envolvendo, assim, a obrigatoriedade dos julgadores em aplicar o direito interpretado, através dos instrumentos elencados no art. 927. Observa-se que o precedente decorre do direito emanado pelo Superior Tribunal de Justiça e pelo Supremo Tribunal Federal. No entanto, a determinação normativa é o início da construção

${ }^{3}$ BRASIL. Senado Federal. Comissão de Juristas Responsável pela Elaboração de Anteprojeto de Código de Processo Civil. Anteprojeto de Código de Processo Civil. Disponível em: https://www. senado.gov.br/senado/novocpc/pdf/Anteprojeto.pdf Acesso em: 28/03/2016

Rev. Ciênc. Juríd. Soc. UNIPAR, v. 19, n. 1, p. 75-85, jan./jun. 2016 
do sistema, posto que, exigirá dos magistrados a adaptação quanto à aplicação do precedente.

Sergio Cruz Arenhart, em coautoria, afirma além de ressignificar a jurisprudência e as súmulas, o novo código introduz o conceito de precedentes. Os precedentes não são equivalentes às decisões judiciais. Eles são razões generalizáveis que podem ser identificadas a partir das decisões judiciais. O precedente é formado a partir da decisão judicial. E porque tem como matéria-prima a decisão, o precedente trabalha essencialmente sobre fatos jurídicos relevantes que compõem o caso examinado pela jurisdição e que determinaram a prolação da decisão da maneira como foi prolatada. Por essa razão, operam necessariamente dentro da moldura dos casos dos quais decorrem. Os precedentes emanam exclusivamente das Cortes Supremas e são sempre obrigatórios - isto é, vinculantes (ARENHART; MARINONI; MITIDIERO, 2015).

Quando se menciona a vinculação do precedente, a obrigatoriedade está na aplicação da tese jurídica ou, da norma jurídica do mesmo, vislumbrando-se, assim, o dever de obedecer à regra jurídica equivalente ao caso. Cumpre, ainda, destacar, Macêdo (2015, p. 226) quando afirma "conjunto de precedentes é um sistema de fontes, mantendo íntegro e coeso o sistema de normas. A norma advinda de um precedente não é diferente da que advém da lei e integra o mesmo conjunto normativo."

Neste aspecto, o mesmo autor, reitera: "ao construir o stare decisis brasileiro é importante que se dê a devida tratativa ao método de determinação da norma do precedente, evitando uma exacerbada preocupação na construção de formas a priori para definir a ratio decidendi e admitindo a sua dimensão argumentativa" (id. Ibid., p. 227).

A busca pelas decisões nos moldes das que foram anteriormente proferidas, revela uma característica favorável à vinculação aos precedentes judiciais que aos poucos consolidam o direito pátrio, proporcionando aos jurisdicionados a estabilidade e segurança nas decisões.

Luiz Guilherme Marinoni (2014, p. 101), ao expor a importância dada a consolidação de um sistema que vislumbre o fortalecimento dos precedentes judiciais, faz uma relação entre a dignidade e a igualdade que essas determinações podem oferecer: "vale dizer que, se há uma clara associação entre generalidade do direito e trato de casos similares do mesmo modo, há igualmente nítida relação entre a pessoalidade e irracionalidade na aplicação do direito [...]"

Cumpre destacar, a justificativa atribuída, pelo mesmo autor, de um sistema de precedentes: "um sistema judicial caracterizado pelo respeito aos precedentes está longe de ser um sistema dotado de uma mera característica técnica." Afirma, que é uma maneira de preservar valores indispensáveis ao Estado de Direito, assim como de viabilizar um modo de viver em que o direito assume sua 
devida dignidade, na medida em que, além de ser aplicado de modo igualitário, pode determinar condutas e gerar um modo de vida marcado pela responsabilidade pessoal (MARINONI, 2014, p. 102).

\section{DEFINIÇÃO DE RATIO DECIDENDI}

Diante da adoção da teoria dos precedentes judiciais, se torna indispensável a compreensão do que, efetivamente, é vinculante na decisão. Neste sentido, os elementos que compõem o precedente servem, justamente, para se evidenciar a parte obrigatória (ratio decidendi) da decisão e aquilo que pode ser desconsiderado (obter dictum). Diante disso, o enfoque será no elemento ratio decidendi, ou seja, a razão de decidir, considerando que o significado de um precedente se encontra na fundamentação da decisão, ou seja, nas razões que levaram à decisão, que ensejaram à fixação do dispositivo (Id. Ibidi.).

Para Luiz Guilherme Marinoni (2014, p. 220), “a razão de decidir, numa primeira perspectiva, é a tese jurídica ou a interpretação da norma consagrada na decisão. De modo que a razão de decidir certamente não se confunde com a fundamentação, mas nela se encontra." Observa-se, assim, que a definição dessas razões ou de ratio decidendi surge da parte vinculante do precedente, obrigando os juízes a considerá-la nos julgamentos posteriores.

Nas palavras de José Miguel Garcia Medina (2016, p. 1234) o que realmente deve ser observado "ora chamado de fundamentos determinantes, ora de entendimento firmado, mas que por comodidade, reunimos sob a expressão ratio decidendi, vem a ser os argumentos principais sem os quais a decisão não teria o mesmo resultado, ou seja, os argumentos que podem ser considerados imprescindíveis".

A razão de decidir não é um elemento estranho no direito brasileiro, todavia, deve ser moldada a fim de caracterizar o real precedente. Conforme Daniel Amorim Assumpção Neves (2016, p. 1313) “a ratio decidendi é o núcleo do precedente, seus fundamentos determinantes, sendo exatamente o que vincula. Afirmar-se que a ratio decidendi do precedente vincula, é indiscutível e a parte fácil de se compreender a eficácia vinculante dos precedentes".

Ao expor sobre a parte vinculante do precedente judicial Marília Siqueira ${ }^{4}$ destaca que "a ratio decidendi é a tese jurídica utilizada pelo órgão julgador, para solucionar o caso concreto, que constitui uma norma geral e abstrata e, por isso, poderá ser aplicada na decisão de outras demandas judiciais fundadas

${ }^{4}$ SIQUEIRA, Marília. Noções fundamentais para o julgamento por aplicação do precedente judicial: necessidade de adaptação a partir do Novo Código de Processo Civil. In: DIDIER JR, Fredie (coord.) et al. Novo CPC doutrina selecionada. Vol. 2. Procedimento comum. $2^{\text {a }}$ ed. Salvador: Editora JusPodivm, 2016, p. 1015. 
em situações semelhantes."

Para Luiz Guilherme Marinoni (2014, p. 220) este elemento pode ser encontrado na fundamentação jurídica da decisão, entretanto "a razão de decidir não se confunde com os fundamentos daquela, isso porque a razão de decidir é elaborada a partir dos elementos presentes no todo da decisão proferida, o qual engloba o relatório, a fundamentação e o dispositivo."

Acerca da ratio decidendi o mesmo autor leciona a decisão "não possui em seu conteúdo apenas teses jurídicas, mas igualmente abordagens periféricas, irrelevantes enquanto vistas como necessárias à decisão do caso. É preciso sublinhar que a ratio decidendi não tem correspondente no processo civil adotado no Brasil, pois não se confunde com a fundamentação e o dispositivo (Id. ibid., 220).”

A ratio decidendi, no common law, é extraída ou elaborada a partir dos elementos da decisão, isto é, da fundamentação, do dispositivo e do relatório. Assim quando relacionada aos chamados requisitos imprescindíveis da sentença, ela certamente é "algo mais". E isso simplesmente porque, na decisão do common law, não se tem em foco somente a segurança jurídica das partes - e, assim, não importa apenas a coisa julgada material-, mas também a segurança dos jurisdicionados, em sua globalidade (Id. Ibid).

Lucas Buril de Macêdo (2015, p. 217) ressalta que nos sistemas jurídicos de common law, a ratio decidendi, cuja terminologia holding, refere-se "às razões de decidir ou razões para a decisão, e configura sinônimo de norma jurídica." Complementa enfatizando que, "no direito brasileiro, o termo é utilizado como razões de decidir ou motivos determinantes pelo Supremo Tribunal Federal e pelo Superior Tribunal de Justiça".

A princípio, tem-se que o precedente judicial é o centro do pronunciamento decisório e será aplicado nas decisões posteriores, logo, nasce como uma regra em um caso específico, posteriormente, "terá ou não o destino de tornar-se a regra de uma série de casos análogos" (TUCCI, 2015).

A formação da ratio decidendi necessita da análise dos elementos objetivos da demanda, apresentados no relatório da decisão, logo, é necessário o estudo da incidência da norma de direito em face dos fatos narrados. "A ratio decidendi envolve as questões levantadas no processo que foram fundamentais para a formação da decisão. Em outras letras, a ratio decidendi consusbstancia os pontos que levaram o julgador a decidir o caso fático daquele modo" (SOARES, 2014).

Sobre a formação da ratio decidendi, expõem Pedro Miranda de Oliveira e Rene José Anderle que transcorrerá de forma gradativa, com a análise do juiz, devidamente reexaminada pelo tribunal local e, quando o caso for submetido aos tribunais superiores, as razões que levaram àquele entendimento se 
apresentam devidamente discutidas nas instância inferiores, estando, portanto, amadurecidas, aptas para o pronunciamento da referida Corte, a fim de emanar o precedente (OLIVEIRA, 2014).

Ademais, explica Luiz Guilherme Marinoni, quando aborda a formação paulatina da ratio decidendi que "algo diferente ocorre quando, em razão do enfrentamento de outra questão, um julgamento ou julgamentos posteriores agregam conteúdo a ratio decidendi, dando-lhe outra conformação." Ressalta, o autor, que a interpretação, pode ampliar ou reduzir um significado pretendido. "Neste caso não há interpretação da antiga ratio, mas formação paulatina da ratio, que vai ganhando corpo à medida que os julgamentos vão sendo proferidos" (MARINONI, 2014, p. 247).

Desse modo, denota-se que a decisão baseada em precedente diz respeito em aplicar as razões essenciais de uma decisão no caso futuro, ante a semelhança tida nos casos. Essa análise do caso concreto determina a técnica de aplicação do precedente.

\section{A RATIO DECIDENDI E A TÉCNICA DA DISTINÇÃO DE CASOS}

Observa-se que o uso do precedente judicial envolve a análise da identidade fática, bem como, dos fundamentos trazidos, já discutidos. O precedente judicial determina os limites da discussão no caso concreto, possibilitando a sua utilização, de forma correta, pelo intérprete da lei. Por conseguinte, "ao aplicar o precedente o juiz deve demonstrar que os fatos são semelhantes e que os argumentos trazidos já foram debatidos, ou, se não foram, expressamente tematizá-los dizendo o porquê não são suficientes para transformar aquela decisão" (OLIVEIRA, 2014).

No que diz respeito ao uso dos precedentes, Michele Taruffo ressalta que o próprio precedente fornece uma regra que pode ser o critério para a decisão do próximo caso ante a identidade dos fatos. Afirma que a análise dos fatos leva o juiz a aplicar o precedente ao próximo caso e "esta análise justifica a aplicação no segundo caso da ratio decidendi aplicada no primeiro". Deve-se notar que, quando se verificam estas condições, um só precedente é suficiente para justificar a decisão do caso sucessivo (TARUFFO, 2016).

O precedente vinculante enseja uma austera delimitação da ratio decidendi, haja vista, a necessidade de interpretação pelo juiz que decidirá o caso correlato, pois, cabe ao juiz, delimitar se o precedente é aplicável ou não, ao caso que está sendo analisado. Assim, a razão de decidir não é estabelecida quando proferida, mas sim, posteriormente, pelo juiz que irá a aplicá-la.

Neste sentido, Jonatas Luiz Moreira de Paula (2016, p. 428-429) salienta que "a elaboração do conhecimento jurídico importa na interpretação das 
normas jurídicas que serão aplicadas à lide. Trata-se de exímio momento de hermenêutica jurídica (...).” Destaca, ainda, que o conhecimento jurídico contém "a apuração do fato comprovado, a definição jurídica da lide e a incidência das normas jurídicas aplicáveis ao caso concreto ou o direito jurisprudencial (a jurisprudência e a súmula vinculantes nos termos do artigo 927 do CPC)." Por isso, se pode acreditar que "no conhecimento jurídico da lide o juiz elabora a sua ratio decidendi, pois nele deverão constar todos os fundamentos jurídicos relevantes que vincularão os demais órgãos jurisdicionais."

Além disso, enfatizando a necessidade da análise fática, Michele Taruffo (2014) afirma que "apenas por meio da referência direta dos fatos da causa se pode determinar qual é a razão jurídica efetiva da decisão, ou seja, a ratio que somente pode ter eficácia de precedente."

Diante disso, necessário destacar que fatos similares devem ser abrangidos, exigindo uma mesma solução, respeitando-se, desse modo, o princípio da igualdade. A análise da identidade fática corresponde a método auxiliar para enquadramento do caso sob julgamento no caso precedente (MARINONI, 2014, p. 228).

O precedente judicial determina os limites da discussão no caso concreto, possibilitando a sua utilização, de forma correta, pelo intérprete da lei. Portanto, "ao aplicar o precedente o juiz deve demonstrar que os fatos são semelhantes e que os argumentos trazidos já foram debatidos, ou, se não foram, expressamente tematizá-los dizendo o porquê não são suficientes para transformar aquela decisão" (OLIVEIRA, 2014).

Neste sentido, o que ora se analisa é a técnica da distinção (distinguishing), ou seja, a aplicação ou não de precedente ao caso que está sob julgamento. Pressupõe-se que diante de dois casos pode haver identidade de fatos, como também pontos que os diferencie, no entanto, cabe verificar o que inegrará a análise da correta aplicação do precedente.

Luiz Guilherme Marinoni ( 2014) salienta "o distinguishing expressa a distinção entre casos para o efeito de se subordinar, ou não, o caso sob julgamento a um precedente. A necessidade de distinguishing exige, como antecedente lógico, da identificação da ratio decidendi do precedente.” Explica que, há necessidade de delimitar a ratio levando-se em conta os fatos do primeiro caso. "Como a ratio espelha o precedente que deriva do caso, trata-se de opor o caso sob julgamento à ratio do precedente decorrente do primeiro caso."

A técnica de distinção busca a constatação da existência de contrariedades entre dois casos, logo, havendo a indicação da aplicação do precedente deverá ser demonstrada a similitude fática dos casos e, diante de eventual discordância, deverão ser apresentados os fatos relevantes que impedem a aplicação do precedente. Observa-se da referida técnica, o potencial de argumentação que 
excede no processo, o que proporciona uma base mais sólida para a correta interpretação e aplicação, ou não, do precedente (PEIXOTO, 2015).

Assim, nas palavras de José Miguel Garcia Medina (2016, p. 1213) "entende-se por distinguishing a recusa de um órgão judicial em aplicar um precedente a um caso atual por considerar este distinto o bastante, de tal modo que a aplicação do precedente a ele geraria injustiça, tendo em vista as peculiaridades do caso atual."

Nesse aspecto, o novo Código de Processo Civil, ao fixar os instrumentos descritos no art. 927, está elencando o rol de provimentos vinculantes, aos quais, juízes e tribunais devem observar, exigindo, para uma correta vinculação ao caso concreto, a necessária compreensão hermenêutica.

Observa-se que, no direito brasileiro, as súmulas vinculantes e as decisões vinculantes possuem o conteúdo já definido, no entanto, a aplicação pelos outros órgãos judiciais não dispensa a atividade interpretativa por parte daquele que julga, a fim da aplicação correta do provimento vinculante. Quanto à aplicação dos provimentos do art. 927, Lênio Streck (2015) ressalta "a aplicação de um precedente é um ato hermenêutico e não mecânico. Do mesmo modo, nenhum provimento vinculante elencado no art. 927 dispensa a atividade interpretativa para sua aplicação." Complementa, ainda, "deverá haver interpretação pelas instâncias inferiores perante a especificidade de cada caso concreto com o intuito de se proferir a solução constitucionalmente adequada para o caso bem como assegurar a integridade e coerência do sistema."

Verifica-se, ainda, que em consonância com o previsto no art. 93, IX da Constituição da República de 1988, o CPC de 2015 destaca a obrigatoriedade da fundamentação das decisões, nos termos do art. 11, bem como, por meio do art. $489, \S 1^{\circ}$, cujo rol, exemplificativo, das hipóteses em que não se considera fundamentada a decisão, especialmente, no inciso VI: "deixar de seguir enunciado de súmula, jurisprudência ou precedente invocado pela parte, sem demonstrar a existência de distinção no caso em julgamento ou a superação do entendimento."

Conforme afirma Jônatas Luiz Moreira de Paula (2016, p. 430) "não bastando o artigo $489, \S 1^{\circ}$, do CPC, a contrario sensu, permite que a decisão judicial inaplique enunciado de súmula, jurisprudência ou precedente invocado pela parte, mas desde que demonstre a existência de distinção no caso em julgamento ou a superação do entendimento."

Assim, diante da aplicação correta da técnica de distinção 'não ocorre uma superação da ratio decidendi originária, mas sim, a criação de uma nova, aplicável a uma situação diferente, ou mesmo um ajuste dos fatos a serem por ela abrangidos." (Id. Ibid. 2015, p. 336)

A técnica da distinção possibilita que a regra estabelecida pelo precedente, permaneça, todavia, sua aplicação se torne menos abrangente. 


\section{CONSIDERAÇÕES FINAIS}

Diante do exposto, observa-se que o Código de Processo Civil de 2015 almeja a devida prestação da tutela jurisdicional de forma uníssona, mediante cumprimento das decisões dos tribunais superiores, embasada nos precedentes com força vinculante. A prática deste sistema, agora, incorporado na atuação jurisdicional, depende do entendimento, pelos operadores do direito, em especial, pelos magistrados, da regra vinculante e, também, da aplicação da técnica que permite a correta vinculação da norma ao caso concreto.

Nota-se, por meio da presente exposição, que muito embora a ratio decidendi não possua um conceito único, é definida como sendo a essência da decisão, ou, os motivos que levaram à determinado julgamento. Assim, a ratio por envolver a análise dos fatos e dos fundamentos jurídicos das questões a serem julgadas pelo juiz de primeira instância, é a parcela da decisão que detém a eficácia vinculante.

No entanto, o uso do precedente no caso concreto não será tarefa fácil, deverá haver a interpretação do caso e de suas razões para que se reconheça a identidade do caso concreto ao precedente. Caso se verifique diferenças relevantes, necessário o uso da técnica da distinção (distinguishing) para o fim de caracterizar a não incidência do precedente, consequentemente, recusar a sua aplicação, porém, de acordo com critérios do uso da técnica, demonstrando respeito aos precedentes.

\section{REFERÊNCIAS}

ARENHART, S. C.; MARINONI, L. G. e MITIDIERO, D. Novo curso de Processo civil. Vol. 2. São Paulo: Editora Revista dos Tribunais, 2015, p. 610611.

BRASIL. Senado Federal. Comissão de Juristas Responsável pela Elaboração de Anteprojeto de Código de Processo Civil. Anteprojeto de Código de Processo Civil. Disponível em: https://www.senado.gov.br/senado/novocpc/pdf/ Anteprojeto.pdf. Acesso em: 28/03/2016

CAMBI, E.; HELLMAN, R. F. Os precedentes e o dever de motivação no Novo Código de Processo Civil. In: DIDIER JR, Fredie (coord.) et al. Novo CPC doutrina selecionada. Vol. 2. Procedimento comum. $2^{\mathrm{a}}$ ed. Salvador: Juspodivm, 2016.

MACÊDO, L. B.de. Contributo para a definição de ratio decidendi na teoria 
brasileira dos precedentes judiciais. In: DIDIER JR., Fredie (coord.) et al. Coleção Grandes Temas do Novo CPC. Vol. 3. Precedentes. Salvador: Juspodivm, 2015.

MARINONI, L. G. A ética dos precedentes: justificativa do novo CPC. São Paulo: Editora Revista dos Tribunais, 2014.

. Precedentes obrigatórios. $3^{\mathrm{a}}$ ed ver. atual. e ampliada. São Paulo: Editora Revista dos Tribunais, 2013.

MEDINA, J. M. G. Direito processual civil moderno. 2 ed. rev. atual. e ampl. São Paulo: Editora Revista dos Tribunais, 2016.

MITIDIERO, D. Precedentes: da persuasão à vinculação. São Paulo: Editora Revista dos Tribunais, 2016.

NEVES, D. A. A. Manual de direito processual civil. Vol. único. 8 ed. Salvador: JusPodivm, 2016.

OLIVEIRA, P. M. de; ANDERLE, R. J. O sistema de precedentes no CPC projetado: engessamento do direito? Revista de Processo. Vol. 232. São Paulo: Revista dos Tribunais. 2014, p. 331-355 (versão eletrônica)

PAUlA, J. L. M. de. Curso de Processo Civil. Processo de conhecimento no novo CPC (Lei n. 13.105/2015 e Lei n.13.256/2016). Belo Horizonte: Editora D’Plácido, 2016.

PEIXOTO, R. O sistema de precedentes desenvolvido pelo CPC/2015 - uma análise sobre a adaptabilidade da distinção (distinguishing) e da distinção inconsistente (inconsistente distinguishing) Revista de Processo. Vol. 248. São Paulo: Revista dos Tribunais. 2015.

STRECK, L.; ABBOUD, G. O NCPC e os precedentes - afinal, do que estamos falando? In: DIDIER JR., Fredie (coord.) et al. Coleção Grandes Temas do Novo CPC. Vol. 3. Precedentes. Salvador: Juspodivm, 2015.

TARUFFO, M. Precedente e jurisprudência. Trad. Chiara de Teffé.

Civilística.com. Rio de Janeiro, a. 3, n.2, jul-dez/2014. Disponível em: <http:// civilística.com/precedente-e-jurisprudencia/>. Acesso em: 24.03.2016

TUCCI, J. R. C. Notas sobre os conceitos de jurisprudência, precedente judicial 
e súmula. Revista Consultor jurídico, 2015. Disponível em http://www. conjur.com.br/2015-jul-07/paradoxo-corte-anotacoes-conceitos-jurisprudenciaprecedente-judicial-sumula Acesso em: 24/03/2016

\title{
THE RATIO DECIDENDI AND ITS CASE FITNESS CONCRETE
}

\begin{abstract}
The Civil Procedure Code 2015 adopted the use of judicial precedents targeting that judgments by superior courts serve as a binding reference in the legal system. However, following the previous system, a judicial precedent cannot be applied unfounded manner, there is the imposition of comparing the case with the paradigm decision. Therefore, it must analyze the element that makes up the previous and operates the binding effect to judicial decisions, the reason that gives rise to the decision (ratio decidendi). First, the analysis will be in the face of its definition and, second, how does the application to the case, especially when necessary to use the technique of distinction (distinguishing) in order to refuse the use of precedent.
\end{abstract}

KEYWORDS: Distinction; New Code of Civil Procedure; Precedent binding; Ratio decidendi.

\section{LA RATIO DECIDENDI Y SU ADECUACIÓN AL CASO CONCRETO}

RESUMEN: El Código de Proceso Civil de 2015 adoptó el uso de los precedentes judiciales, buscando con que las decisiones proferidas por los tribunales superiores sirvan como referencia vinculante en el ordenamiento jurídico. Sin embargo, siguiendo el sistema de precedentes, un precedente judicial no podrá ser aplicado de manera infundada, hay la imposición de compararse el caso concreto con la decisión paradigma. Por lo tanto, cumple analizar el elemento que compone el precedente y que opera la eficacia vinculante a las decisiones judiciales, el motivo que da lugar a la decisión (ratio decidendi). En primer lugar, el análisis será en caso de su definición y, en segundo lugar, cómo ocurre la aplicación al caso concreto, sobre todo, cuando es necesario el uso de la técnica distinción (distinguishing), con el fin de rechazar el uso del precedente.

PALABRAS CLAVE: Distinción; Nuevo Código de Proceso Civil; Precedentes vinculantes; Ratio decidendi. 